\title{
Personal Medical Information Management: The Information Privacy Culture of Asian Countries
}

\author{
Suhaila Samsuri and Zuraini Ismail
}

\begin{abstract}
Asian communities have a distinctive concept in perceiving the value of information privacy, which is completely unique from the description set by western countries. This paper gathers the definition and the theory of information privacy culture. Based on the culture dimension theory of Hofstede, it attempts to reveal the perception and concern of Asian countries towards the privacy of its personal information. A survey was conducted in one of the public universities in Malaysia in order to gauge the 'power distance' and 'collectivistic' culture characteristic in the public perception towards their personal medical information privacy. The result unveils its support for both theories, despite the increasing trend in privacy appreciation among the post-graduate and professionals in Malaysia. In addition, the result also shows a notable increase in the public privacy concern especially over the management of their personal medical information (PMI) in the hospital information system (HIS). The findings should be considered as valuable in designing the patient's electronic medical record (EMR) system in HIS with the incorporation of privacy preservation elements.
\end{abstract}

Index Terms-Information privacy culture, privacy concern, personal medical information, hospital information system.

\section{INTRODUCTION}

In this decade where data are mostly managed by computers and digitally stored, the discussion on the subject of information privacy is becoming inevitable. In recent years, information privacy has been widely debated, disputed and become a popular topic among the personal information management system researches. The rapid advancement of technology in Asia has triggered much public concern over the safety of their personal information being collected, regardless by the government or private sector. This study endeavors to assess the trend and concern among Asian people specifically over their personal medical information as compared against the established privacy pattern among the westerners. Personal medical or health information that is being collected in the hospital is becoming one of the major concerns among citizen. This statement was emphasized based on the survey findings in the evaluation of the public concern in developed western countries with regards to their personal medical or health information [1]-[8].

Nevertheless, according to [9], people have complex

Manuscript received March 5, 2013; revised May 6, 2013. This study was funded by the Research University Grant (RUG) from Universiti Teknologi Malaysia (UTM) and Ministry of Higher Education (MOHE) Malaysia with project number Q.K 130000.2138.01H98

Suhaila Samsuri is with International Islamic University Malaysia under Kulliyyah of Information and Communication Technology (email: umysue@gmail.com)

Zuraini Ismail is with Advanced Informatics School of Universiti Teknology Malaysia (e-mail: zurainisma@ic.utm.my). relationship with the social norms whereby it differs from one place to another and has a dynamic correlation with technology. Several methods can be applied in observing this trend including the review of information privacy or data protection law that is being practiced [10]-[13], the policies established or simply the culture value in that particular country [14]-[19]. Certain researchers prefer to observe the patient's personal information under the management of the government and commercial sectors from the public perspective. It is essential to protect the privacy of patient's medical information in order to gain the trust from the public and improve the quality of health care provided by hospital. If the authority fails to preserve the privacy of the patient's medical information, it allows numerous unwanted crimes to ensue and subsequently jeopardize the patients' reputations such as stolen identity incidents or impairment of employment record. However, there is lack of research ever conducted over the privacy of personal information in Asian countries.

Hence, this paper attempts to reveal the perception and concern of several Asian countries and how their culture have given the influence towards personal medical or health information privacy in the hospital information system (HIS). This paper proceeds with section 2 in reviewing the information privacy definitions and various Asian concepts. The section 3 will be followed to conclude this study.

\section{ASIAN INFORMATION PRIVACY CONCEPT}

Milberg et al [20] suggested the possibility of individuals in different countries would exhibit different levels of concern regarding information privacy at a given point of time. This statement is derived from the facts produced by Westin [21] that societies do value privacy in some form, but the expression of the privacy varies significantly across cultures. Culture is capable in affecting the notion of privacy as far as to what extend it needs or deserve protection and the level of its importance [22], [23]. This observation by Westin was strengthened by the Bellman et al [17] study which investigates in the differences of international privacy concern based on the culture theory of Hofstede [24], [25]. According to studies by Hofstede [26], [27] on culture dimension, Asian countries commonly are categorized under large 'power distance' societies and 'collectivism' dimension. Power distance can be described as the way the society deals with the fact that people are unequal, including in power and wealth. It involves not only those in the high echelon of power and control but also those at the bottom of the power hierarchy. Those countries which have high power distance index (PDI) tend to accept the class divisions within society. People have their own shelters and accept this inequality 
without further questions. In 'collectivist' societies, people are belonged to an 'in-group' that takes care of each other in exchange for loyalty. This culture is apparent usually among close, long-term commitment and relationship, such as between family members, extended family or among members of an organization. The loyalty often overrides and is paramount in most of societal rules and regulations. Any offence among its members will deliver embarrassment to the group and result in loss of face.

These two terms; 'power distance' and 'collectivism' are among the five of Hoftsede culture dimensions that are included in our study of Asian information privacy culture. Bellman et al [17], [18] and Milberg et al [20], [28] then found the significant influence between these culture values with information privacy concerns. People from countries with relatively higher scores on PDI have indicated lower levels of overall concern about information privacy and unauthorized access [17]. On the same note, Milberg et al [28] unveiled that people in high 'individualism' countries, which means low in 'collectivism' exhibit higher levels of concern for information privacy. On the other hand, people in 'collectivism' countries have low concerns towards their information privacy. The statement are supported by the findings from several studies, which stated that personal information privacy control in Asia Pacific is relatively complex due to the diversity in cultures, types of governments, differences in legislation and variety of business practices [13], [16], [23], [29].

From cultural standpoint, Malaysia is reported to have the highest PDI value of 104 as compared with other countries [30]. This rationalized that Malaysian society is best characterized as the hierarchical societal class where every individual already accepts his or her place in the society without any further justification required. As a typical subordinate in an organization, Malaysian people are the kind of people who expect to be told what to do. Usually, the ideal leader for them is a benevolent autocrat. The score for individualistic level is only 26 , which makes them belong to a collectivistic society. It also indicates that the loyalty for long term commitment to family, extended family or extended relationship is inevitable. This can also be an attribute for the delay in enacting as well as enforcing their Personal Data Protection Act (PDPA, 2010). The authority may deduce that the public is still indifferent to the need of protecting their information privacy rights.

In terms of protecting the personal health information privacy, one of the Malaysia Hospital Information System's developer teams from the Ministry of Health (MOH) admitted that as a Malaysian culture, the public rarely argue and dispute the government policies and have doubts on how their personal information are being handled [31]. These preliminary findings are in accordance to Hofstede [30]. However, the preliminary survey by Lallmahamood [32] among the Malaysian internet users indicated that majority (94.2\%) of respondents have expressed their concern on the privacy of their personal information over the internet, which make it similar with the number stated by Westin in US [33]. This study is also supported by the Sarabdeen article [34], which claimed that users' concern over their information privacy were able to influence the successful implementation of the electronic health information. In Malaysia's scenario, the contradiction between the stances of the Ministry of Health Malaysia with the public opinion exists, even though the public usually do not file their complaint directly with the authority. This further reinforces that in a high PDI country, individuals accept their place without further justification, although they may not agree with the actions imposed by the government.

\section{Methodology}

A survey was conducted in 2011 to evaluate the public personal health information privacy concern among the educated and professionals Malaysian at Universiti Teknologi Malaysia Kuala Lumpur in order to examine the trend of information privacy culture in Malaysia. The survey instrument was designed and adapted based on the previous study models [11], [12], [35]-[38]. In this paper, the survey is reported only on the aspect of public general privacy awareness and their concern over the importance of personal medical information privacy.

\section{FINDINGS}

The survey returned for about 202 respondents and it shows that generally, the information privacy awareness among post-graduate students and professional Malaysian respondents is quite high. Based on the graph shown in Fig. 1, majority of the respondents $(83.7 \%)$ were very concern on their information privacy. Almost half of them (49.5\%) ever placed their trust with the government system in handling their personal information. Slightly more than half of respondents $(56.4 \%)$ expressed their concern over their personal information being displayed in public. While majority of them $(63.9 \%)$ were highly concerned on the selling and trading of their personal information among companies in Malaysia.

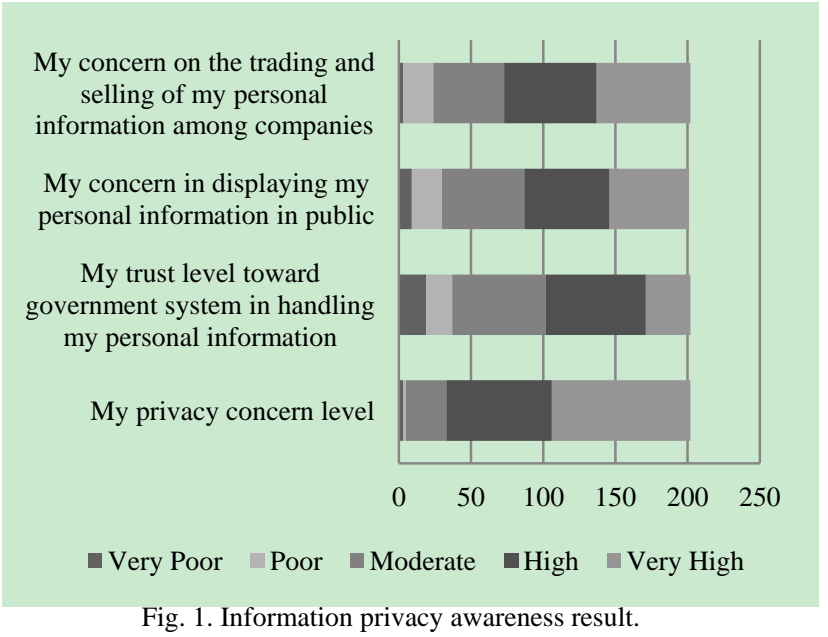

Nearly three quarters of respondents $(72.8 \%)$ claim that they are more comfortable to give their most sensitive medical information to hospital staffs that they have get acquainted personally as compared with any other unfamiliar staffs, refer to Table I. The finding seems to support the Hofstede's 'collectivist' culture theory over Malaysian society, where the faith in the grouping style is the most popular culture in Asian countries, and still have a strong presence in Malaysian culture. In strengthening further, 
majority of respondents $(84.7 \%)$ admit that they are more comfortable to share their sensitive medical issues with people who are close to them (i.e. extended family, next of kin, relatives or best friend) rather than to strangers. The mean value for this study frequency distribution was defined as low (1-2.33), moderate (2.34-3.66) and high (3.67-5) [39]. Out of seven items displayed in the table, six items are categorized under high value, which means most of the respondents have high concern over almost each of the conditions given. This study shows that culture values of a particular region are still important factors to be considered especially in designing a new technology system for the educated and experienced users. It is essential in achieving the balance between the government requirements and public necessity.

TABLE I: PRIVACY AWARENESS ON HEALTH INFORMATION

\begin{tabular}{|c|c|c|c|c|}
\hline $\begin{array}{l}\text { Privacy Awareness on } \\
\text { Medical/Health Information }\end{array}$ & $\begin{array}{c}\text { Negative } \\
\text { Response }(\%)\end{array}$ & $\begin{array}{l}\text { Positive } \\
\text { Response } \\
\quad(\%)\end{array}$ & Mean & $\begin{array}{l}\text { Std } \\
\text { deviation }\end{array}$ \\
\hline $\begin{array}{l}\text { I am ready to have my personal } \\
\text { medical information online }\end{array}$ & $\begin{array}{c}43 \\
(21.3)\end{array}$ & $\begin{array}{c}105 \\
(51.98)\end{array}$ & 3.40 & 1.138 \\
\hline $\begin{array}{l}\text { Electronic medical record is able } \\
\text { to protect integrity, security, } \\
\text { privacy and confidentiality of } \\
\text { patients medical information }\end{array}$ & $\begin{array}{c}25 \\
(12.4)\end{array}$ & $\begin{array}{c}117 \\
(57.92)\end{array}$ & 3.71 & 1.041 \\
\hline $\begin{array}{l}\text { Personal Medical Information } \\
\text { (PMI) is considered very private } \\
\text { and confidential }\end{array}$ & $\begin{array}{c}15 \\
(7.43)\end{array}$ & $\begin{array}{c}148 \\
(73.27)\end{array}$ & 3.96 & 0.953 \\
\hline $\begin{array}{l}\text { Government hospital is the best } \\
\text { in protecting patients' medical } \\
\text { information }\end{array}$ & $\begin{array}{c}19 \\
(9.41)\end{array}$ & $\begin{array}{c}124 \\
(61.39)\end{array}$ & 3.75 & 0.981 \\
\hline $\begin{array}{l}\text { Patients have the right to ask for } \\
\text { special privacy protection on } \\
\text { their medical information }\end{array}$ & $\begin{array}{c}8 \\
(3.96)\end{array}$ & $\begin{array}{c}178 \\
(88.12)\end{array}$ & 4.44 & 0.857 \\
\hline $\begin{array}{l}\text { I am more comfortable to give } \\
\text { my most sensitive medical } \\
\text { information to hospital staff that } \\
\text { I already know personally than } \\
\text { any other unknown staff }\end{array}$ & $\begin{array}{c}18 \\
(8.91)\end{array}$ & $\begin{array}{c}147 \\
(72.77)\end{array}$ & 3.93 & 0.972 \\
\hline $\begin{array}{l}\text { I am more comfortable to share } \\
\text { my sensitive medical case with } \\
\text { people who are close to me rather } \\
\text { than a person who know nothing } \\
\text { about me personally }\end{array}$ & $\begin{array}{c}10 \\
(4.95)\end{array}$ & $\begin{array}{c}171 \\
(84.65)\end{array}$ & 4.32 & 0.904 \\
\hline
\end{tabular}

This study then enters into a more discreet PMI subject that will be managed in electronic medical record (EMR) of the HIS. After examining the public opinions in terms of their cultural behavior, the study investigates their opinion on the management of their PMI based on the Individual Privacy Concern dimensions by Smith [40], inclusive of the elements of collection, secondary use, improper access and error.

Based on the result in Table II, majority of the respondents reported to have concern over their PMI being managed in hospitals. The value of positive response, which derived from the value of agree and strongly agree recorded to have more than half $(50 \%)$ for all the conditions in privacy concern dimensions; the collection, secondary use, improper access and mistake of PMI. The mean value for privacy concern frequency distribution was also defined as low (1-2.33), moderate (2.34-3.66) and high (3.67-5) [39]. Except for the first condition which falls under the moderate value, the rest are categorized under high value of means, which are above 3.67. In terms of PMI collection, the respondents generally do not really feel disturbed if any of the hospital staffs confronted them for their sensitive PMI (i.e. mental health problem, sexual disease etc.). However, they might re-think their decision before agreeing to provide it to them. They are really concern if the hospital intends to ask or collect too much sensitive information about them.

Secondly, for PMI secondary use, respondents agree that hospital should not use PMI for any other than medical purposes such as research or commercial, unless it has been authorized by the patients who provided the information. They remarked clearly that hospital should never share their PMI with other parties such as insurers or other health agencies, unless it has been authorized by the patients who provided the information.

Thirdly, in terms of improper access to PMI dimensions, respondents have high expectation for a hospital management to devote more effort in finding ways to prevent unauthorized access to their PMI. HIS should be equipped with security mechanism (e.g. password protected or access via fingerprint, etc) in order to ensure the computer databases that contained PMI are protected from unauthorized access, regardless of how much the cost may be incurred.

Finally, in terms of error or mistake in PMI, the respondents require that all PMI in computer databases should have a mechanism that enables the double-checking of the accuracy of PMI, regardless of the amount of cost incurred. Government HIS hospitals should have better or improved procedures in correcting the errors of PMI in the system. In addition, more time and effort should be allocated to verify the accuracy of the personal medical information in their databases.

\section{CONCLUSION}

This study is immensely valuable in providing a guideline for developing and implementing a HIS successfully based on the public requirement especially in handling their PMI. Since the PMI is owned and provided by the public or patient, their opinion on the way of information is handled must not be discounted. This paper only reports a part of the study, which concentrates more on the privacy culture and public personal information privacy concern. A broader aspect of information protection has been designed to ensure the comprehensiveness of the research, such as law, ethics and technology. Furthermore, this study only concentrates on the educated and professional samples, which make up a population that is mostly influential in Malaysia's situation. They have the potential to give input to the government for the improvement of system even though their opinion may not be representative of the whole Malaysian population.

For this study, it can be summarized that post-graduate and professional Malaysians are truly concern over their information privacy and demand a systematic and secured procedures in managing their PMI in HIS hospitals. Although this finding might not be aligned with the previous studies which stated that Asian people has lack of concern over their personal information privacy, the study does still conform with the theory of culture by Hofstede, who stated that 
Malaysia has the 'power distance' and 'collectivistic' culture. His study also found the existence of that culture, where Malaysian still entrust and agree that the government is the most reliable party in handling their PMI (power distance character). In addition, Malaysian are still comfortable in sharing their personal information with their groups, namely people or hospital staffs who are closed to them or knowledgeable about them, relatives and family (collectivistic character). Finally, it can be deduced that the concept of privacy among educated and professional Malaysian is considered to be uniquely distinctive from the western practice.

TABLE II: PERSONAL MEDICAL INFORMATION PRIVACY CONCERN

\begin{tabular}{|c|c|c|c|}
\hline $\begin{array}{l}\text { Privacy Concern over PMI } \\
\text { Management in HIS }\end{array}$ & $\begin{array}{c}\text { Negative } \\
\text { Response } \\
(\%)\end{array}$ & $\begin{array}{c}\text { Positive } \\
\text { Response } \\
(\%)\end{array}$ & Mean $\begin{array}{c}\text { Std. } \\
\text { Deviation }\end{array}$ \\
\hline
\end{tabular}

\section{Collection}

It usually bothers me when hospital staff asks me for my sensitive medical information.

$\begin{array}{cccc}31 & 103 & 3.51 & 1.080\end{array}$

When hospital staff asks me sensitive medical information, I sometimes think twice before providing it.

$\begin{array}{cccc}24 & 110 & 3.70 & 1.061\end{array}$

I'm concerned that hospital is collecting too much sensitive information about me.

$\begin{array}{cccc}9 & 137 & 3.97 & 0.892 \\ (4.46) & (67.82) & & \end{array}$

\section{Secondary Use}

Hospital should not use personal medical information for any other purpose unless it has been authorized by the patients who provided the information.

Hospital should never share personal medical information with other parties unless it has been authorized by the patients who provided the information.

$\begin{array}{cccc}2 & 165 & 4.26 & 0.795 \\ (0.99) & (81.68) & & \\ & & & \\ & & & \\ 1 & 168 & & \\ (0.50) & (83.17) & 4.40 & 0.774\end{array}$

\section{Improper Access}

Hospital should devote more time and effort to preventing unauthorized access to personal medical information.

Computer databases that contain personal information should be protected from unauthorized access - no matter how much it costs.

\section{Error}

All the personal medical information in computer databases should be double-checked for accuracy no matter how much this costs.

Hospital should have better procedures to correct errors in personal information

Hospital should devote more time and effort to verifying the accuracy of the personal medical information in their databases.

\section{REFERENCES}

[1] G. Bansal, F. Z. Mariam, and D. Gefen, "The impact of personal dispositions on information sensitivity, privacy concern and trust in disclosing health information online," Decision Support Systems, vol. 49 , issue 2, pp. 138-150, May 2010.

[2] T. Bodenheimer and K. Grumbach, "Electronic technology: a spark to revitalize primary care?" Journal of the American Medical Association, vol. 290, no. 2, pp. 259-264, 2003.

[3] J.D. Cantor, "Privacy protections for cybercharts: an update on the law," Journal of the American Medical Association, vol. 285, no. 13, pp. 1767,2001 .

[4] Harris-Interactive, A. F. Westin, The Harris Poll: \#46, Harris Interactive, New York, 2002.

[5] D. Masys, D. Baker, A. Butros, and K. E. Kowles, "Giving patients access to their medical records via the Internet: the PCASSO experience," Journal of American Medical Informatics Association, vol. 9, no. 2, pp. 181-191, 2002.

[6] E. H. Shortliffe, Diffusion of Innovations, 4th ed., New York: The Free Press, 1999.

[7] K. A. Stewart and A. H. Segars, "An empirical examination of the concern for information privacy instrument," Information System Research, vol. 13, no. 1, pp. 36-49, 2002.

[8] A. F. Westin, "Social and political dimensions of privacy," Journal of Social Issues, vol. 59, no. 2, pp. 431-453, 2003.

[9] R. Cullen, "Culture, identity and information privacy in the age of digital government," Online Information Review, vol. 33, no. 3, pp. 405-421, 2009.

[10] M. Crompton, "Overview of Asian Privacy Law Lesson Learned and Possible Ways Forward," in Privacy Symposium, June 2006, Ch. 3.

[11] Freshfields Bruckhaus Deringer, Data Privacy Protection across Asia: A Regional Perspective, October 2008.

[12] G. Kennedy, S. Doyle, B. Lui and Contributors, "Data protection in the Asia-Pacific region," Computer Law \& Security Review, vol. 25, pp. 59-68, 2009.

[13] Privacy International. (November 2009). Privacy in Asia Final Report of Scoping Project. [Online]. Avalaible: www.privacyinternational.org,

[14] B. Moore Jr., Privacy: Studies on Social And Cultural History, New York: Random House Inc (P), 1984.

[15] K. Ishikawa, "Health data use and protection policy; based on differences by cultural and social environment," International Journal of Medical Informatics, vol. 60, pp. 119-125, 2000.

[16] J. C. Tam, "Personal data privacy in the Asia Pacific: a real possibility," in Proc. The tenth conference on Computers, freedom and privacy: challenging the assumptions, 2001, pp. 259-262.

[17] S. Bellman, E. J. Johnson, S. J. Kobrin, and G. L. Lohse, International Differences in Information Privacy Concern: Implications for the Globalization of Electronic Commerce, Advances in Consumer Research, vol. 31, pp. 362-363, May 2003.

[18] S. Bellman, E. J. Johnson, S. J. Kobrin, and G. L. Lohse, "International differences in information privacy concern: a global survey of consumers," The Information Society: An International Journal, vol. 20, no. 5, pp. 313-324, 2004.

[19] K. Murata, "Rethinking the concept of the right to information privacy: a Japanese Perspective," Journal of Information, Communication \& Ethics in Society, vol. 6, no. 3, pp. 233-245, 2008.

[20] S. J. Milberg, S. J. Burke, H. J. Smith, and E. A. Kallman, "Values personal information privacy and regulatory approaches," Communication of the ACM, vol. 38, no. 12, pp. 65-74, 1995.

[21] A. F. Westin, Privacy and Freedom, New York: Atheneum, 1967.

[22] R. T. de George, The Ethics of Information Technology and Business, vol. 3, Oxford: Blackwell, 2003.

[23] P. Kumaraguru and L. Cranor, "Privacy in India: Attitudes and Awareness, Privacy Enhancing Technologies," Lecture Notes in Computer Science, vol. 3856, pp. 243-258, 2006.

[24] G. Hofstede, Culture's Consequences: International Differences in Work-Related Values, Beverly Hills/London: SAGE Publications, 1980.

[25] G. Hofstede, Cultural and Organizations:Software of the Mind: Intercultural Cooperation and its importance for survival, New York: McGraw Hill, 1991.

[26] G. Hofstede, The cultural relativity of organizational practices and theories, Institute for Research on Intercultural Cooperation (IRIC), Journal of International Business Studies, vol. 14, issue 2, pp. 75-89, 1983.

[27] G. Hofstede, "The Business of International: Business is Culture," International Business Review, vol. 3, no. 1, pp. 114, 1994. 
[28] S. J. Milberg, S. J. Burke, and H. J. Smith, "Information privacy: corporate management and national regulation," Organization Science, vol. 11 , no. 1 , pp. 35-57, 2000.

[29] K. Kitiyadisai, "Privacy rights and protection: foreign values in modern Thai context," Ethics and Information Technology, vol. 7, pp $17-26,2005$

[30] G. Hofstede, Culture Consequences: Comparing Values, Behaviours, Institutions and Organizations across Nations, 2nd ed., Thousand Oaks, CA:SAGE, 2000.

[31] S. Samsuri, Z. Ismail, and R. Ahmad, "Towards implementing a privacy policy: An observation on existing practices in Hospital Information System," Journal of e-health Management, vol. 2011, pp. 9, 2010.

[32] M. Lallmahamood, Privacy over the Internet in Malaysia: A survey of general concerns and preferences among private individuals, 2008

[33] A. F. Westin, How the Public Views Privacy and Health Research, Institute of Medicine, 2007

[34] J. Sarabdeen, "E-health data privacy: How far it is protected?" Communications of the IBIMA, vol. 1, pp. 110-117, 2008

[35] P. Kumaraguru and L. Cranor, "Privacy in India: attitudes and awareness, privacy enhancing technologies," Lecture Notes in Computer Science, vol. 3856, pp. 243-258, 2006.

[36] Harris-Interactive, "Americans Trust Health Providers to Handle Personal Information in Secure Manner," in BBC World News America/The Harris Poll, 2009.

[37] M. Smit, M. McAllister, and J. Slonim, Privacy of Electronic Health Records: Public Opinion and Practicalities, NAEC, 2005.

[38] D. Krane, Harris-Interactive, Many U.S. Adults are Satisfied with Use of Their Personal Health Information, The Harris Poll \#27, March 2007.

[39] A. Samah. (2012). Basic Statistical Concepts. Training Materials, Universiti Putra Malaysia. [Online]. Available: http://ace.upm.edu.my/ bas/SelectedLinks.htm
[40] H. J. Smith, S. J. Milberg, and S. J. Burke, "Information privacy: measuring individuals' concerns about organizational practices," MIS Quarterly, vol. 20, no. 2, pp. 167-196, 1996.

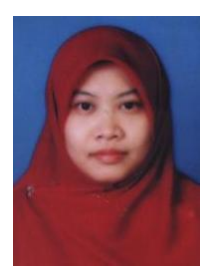

Suhaila Samsuri currently is a Ph.D candidate at Universiti Teknologi Malaysia (UTM) under the Advanced Informatics School. She is doing a research on the topic of information privacy for personal medical information being managed in hospital information system (HIS). Her study is sponsored under the fellowship scheme of International Islamic University Malaysia (IIUM) and Ministry of Higher Education Malaysia (MOHE). She also hold a Maste of Science majoring in medical informatics and multimedia from Universiti Putra Malaysia (UPM) in 2007, where she has developed a breast health kiosk which is able to assist the breast cancer diagnosis. Her first degree is in management information system which she pursue at International Islamic University Malaysia (IIUM) in 2001 with her final project was a research on e-commerce in islamic perspective. Ms Samsuri works have been published in several proceedings and journals. Her research interest including information security and privacy, human computer interactions, medical informatics or e-health and multimedia and animation.

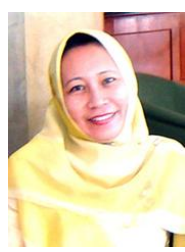

Zuraini Ismail (Ph.D) is an associsate professor at Advanced Informatics School, Universiti Teknologi Malaysia. Her research interest including Information Systems, Data Base Systems Information Security Policy, Information Security - Awareness and Ethics, Physical Security Operations and Management, Cyber Security, Knowledge Management, e-Government and IT Outsourcing. 